\title{
A língua inglesa e os cursos jurídicos
}

\section{Luiz Eduardo Meneses Oliveira}

Professor Adjunto do Departamento de Letras da

Universidade Federal de Sergipe e do Núcleo

Compartilhado de Pós-Graduação em Letras UFS/

UFAL. Atualmente, coordena o Grupo de

Pesquisa "História do ensino das línguas no

Brasil".

Resumo: Este artigo pretende investigar o modo pelo qual a consolidação da Língua Inglesa como disciplina escolar relaciona-se com os discursos que justificam sua introdução entre as matérias preparatórias aos Cursos Jurídicos do Império brasileiro, buscando mostrar o vínculo entre a anglofilia de alguns parlamentares e professores da época e a idéia de que o estudo do inglês serviria como antídoto contra o veneno do excessivo liberalismo dos franceses, cuja filosofia ameaçava 0 altar e o trono.

Abstract: This article intends to investigate the way how the consolidation of the English languge as a school discipline is related to the discourses which justify its introduction among the preparatory subjects to the courses of law of the Brazilian Empire, trying to show the link between some Anglophile congressmen and teachers of the time and the idea that the study of English could serve as an antidote against the excessive liberalism of the French, whose philosophy threatened the altar and the throne.
Palavras-chave: Cursos jurídicos; disciplina escolar; lingua inglesa
Keywords: law courses; school discipline;

English language 
. 
As primeiras tentativas de instituição dos Cursos Jurídicos no Brasil confundem-se com os debates em torno da criação de uma Universidade, na Assembléia Constituinte de 1823. Na sessão de 14 de junho, José Feliciano Fernandes Pinheiro (1744-1847), o Visconde de S. Leopoldo, referia-se aos "duros tratamentos e oppressão"' experimentados pela mocidade brasileira que se dirigia à Universidade de Coimbra para estudar, propondo que se estabelecesse uma Universidade no Império do Brasil, com assento na cidade de S. Paulo, "pelas vantagens naturaes, e razões de conveniencia geral" (BRASIL, 1874).

Em 19 de agosto, Martim Francisco (1775-1844), em nome da Comissão de Instrução Pública, leu um projeto de lei criando "duas Universidades, uma na cidade de S. Paulo, e outra na de Olinda, nas quaes se ensinarão todas as sciencias e bellas letras" (art. 1.). O artigo quarto estabelecia que fosse criado um Curso Jurídico na cidade de São Paulo, com "mestres idoneos" e uso provisório dos Estatutos da Universidade de Coimbra. Sendo requerida e aprovada a urgência da matéria, mandou-se imprimir o projeto a ser debatido.

As discussões que se seguiram sobre o tema foram das mais interessantes da Constituinte de 1823, cada deputado defendendo sua província como sede para aquelas importantes instituições. Uns concordavam com Fernandes Pinheiro e elegiam como assento São Paulo, outros preferiam a Corte, pelo acesso às Artes e às Ciências e melhor controle pelo governo. O baiano José da Silva Lisboa $^{2}$, em sessão de 28 de agosto, defendia a criação da Universidade da Bahia, censurando São Paulo pela pronúncia desagradável dos paulistas, "cujo dialecto é o mais notavel" (BRASIL, 1874). Segundo Vampré (1924, p. 10), "ao mesmo tempo em que estes debates ocorriam na Constituinte, apresentavam-se algumas villas do Imperio, das mais remotas, e das menos conhecidas, desejosas de se tornarem um dia Coimbrãs do Brasil".

O debate sobre o projeto, no entanto, foi interrompido, pois em 12 de novembro D. Pedro I
${ }^{1}$ A ortografia e a pontuação dos documentos citados foram mantidas, em fidelidade ao vocabulário e ao estilo da época.

${ }^{2}$ Trata-se do Visconde de Cairu (1756-1835). Seu papel de mecenas pode ser rastreado nos agradecimentose dedicatórias dos compêndios aprovados pelo Desembargo do Paço, onde desempenhava a função de Censor Régio, pois eles representam boas pistas para se avaliar a sua proteção dos autores autorizados, quando se interessava, de alguma forma, em sua promoção ou na do conteúdo de sua obra, caso de Arte ingleza, escrita pelo Padre Guilherme Tilbury. 
dissolveu a Constituinte, outorgando meses depois a Constituição de 1824. Em 9 de janeiro do ano seguinte, um decreto assinado pelo Conselheiro e Ministro do Império Estevão Ribeiro de Rezende criou provisoriamente um Curso Jurídico na Corte, "com as convenientes Cadeiras, e Lentes, e com o methodo, formalidade, regulamento e instrucções", sendo seus Estatutos elaborados por Luís José de Carvalho e Mello, o Visconde da Cachoeira (BRASIL, 1885). Ao que parece, o decreto não teve execução, pois foi abandonado em proveito de um novo projeto de lei apresentado pelo Cônego da Capela Imperial Januário da Cunha Barbosa (1780-1846), em 5 de julho de 1826.

O projeto apresentado pelo autor do Parnaso Brasileiro (1829-1832) estabelecia, no artigo primeiro, que o Curso Jurídico, "ou de sciencias sociaes", teria assento no Rio de Janeiro, e no sétimo que os estudantes, como requisito de matrícula, deveriam apresentar "certidão de idade, e de approvação em grammatica latina, rhetorica, philosophia racional e moral". Os Exames, de acordo com o mesmo artigo, seriam feitos por "tres professores publicos, presididos pelo decano dos lentes" (BRASIL, 1982).

Nos debates seguintes, discutiu-se longamente sobre a sede do curso e o Plano de Estudos a ser adotado. Francisco de Paula Souza e Mello (1791-1851), na sessão de 8 de agosto, depois de um extenso discurso do bacharel português José Clemente Pereira (1787-1854) contra o excesso de distrações da Corte, sugeriu a já conhecida proposta da criação de dois Cursos Jurídicos, um em São Paulo e outro em Olinda, sendo sua emenda aprovada por unanimidade. Clemente Pereira, no dia seguinte, em recusa à sugestão do Capitão Mor Custódio Dias, que pedia o adiamento da discussão, propôs que os Estatutos, enquanto não fossem elaborados, se guiassem pelo projeto do Visconde da Cachoeira.

Na sessão de 11 de agosto, após uma discussão sobre a competência da escolha e aprovação dos compêndios, objeto do artigo sexto, passou-se ao artigo 
seguinte, que dispunha sobre os requisitos de ingresso no curso. O bacharel mineiro Bernardo Pereira de Vasconcelos (1795-1850), ao criticar o excesso de Direito Romano ensinado no curso coimbrão, propôs que se suprimissem desde o artigo sétimo, sobre os estudos preliminares, ou "Exames de Preparatórios", até o 15, que regulava a competência da direção e inspeção dos estabelecimentos, alegando que tais matérias já se achavam reguladas pelos Estatutos do Visconde da Cachoeira, "que são quase uma copia fiel dos da Universidade de Coimbra" (BRASIL, 1982). O médico baiano Antonio Ferreira França (17751848), pedindo a palavra, defendeu, ao contrário, a regulamentação dos preparatórios, afirmando que os Estatutos do Visconde foram aprovados somente na parte aplicável aos novos cursos:

Não se deve passar por isto á carreira, nós havemos de tratar dos estudos preliminares, como um objecto essencial, e por isso opponho-me a que sejão supprimidos estes artigos antes quero que sejão discutidos para vermos, e provermos o melhor. Eu não tenho presentes esses estatutos, porém segundo a minha lembrança, elles tratão a geometria como uma doutrina indifferente, e nós devemos olhar melhor esta sciencia. Além disto eu quizera que os preparatorios fossem mais do que lá se acham, e por outra ordem muito diversa. Portanto, meus senhores, eu me pronuncio contra a suppressão, entrem esses artigos em discussão, e organise-se um systema melhor de preparatorios. (BRASIL, 1982, p. 119)

Paula Souza (1791-1852) prộôs uma emenda na qual os artigos sétimo e oitavo reduziam-se ao seguinte: "nenhum estudante se poderá matricular no curso juridico, sem ter 15 annos completos apresentando certidão de idade, e de approvação em grammatica latina, rhetorica, philosophia racional, e geometria. Estes exames serão feitos por dous professores publicos, presididos pelo decano da faculdade", 
sendo apoiado. Outro médico representante da Bahia, José Lino Coutinho (1784-1836), discursou contra a Filosofia Racional e Moral, defendendo a importância do Latim e da Retórica: "nem sei o que seja uma tal philosophia como preparatorio, porque não se pode nada disto saber, senão depois de se haver aprendido muitas outras cousas". Para o deputado, os únicos Preparatórios necessários eram a Gramática Latina, a Retórica e a Geometria. Clemente Pereira não concordava com o colega, expondo a importância de todos os Preparatórios, inclusive das Línguas Estrangeiras Modernas:

${ }^{3}$ Para Ferreira França, o estudo da língua grega facilitava o do latim, do português, do francês e do inglês, pois "aquella lingua comprehende, por assim dizer, a todas as outras" (BRASIL, 1982, p. 122).

' Para Tilbury, os autores ingleses poderiam servir como um "anthidoto" contra o veneno do excessivo liberalismo dos franceses, que, com sua filosofia, "já entre nós tem ameaçado ao Altar e ao Throno" (TILBURY, 1827: iv).
Todos os outros preparatorios são muito necessarios, eu ainda addicionaria o exame das linguas franceza, e ingleza, porque é um meio de adquirir luzes. A geometria é indispensavel: sem ella como se podem adquirir ideas exactas em economia politica? Quanto á idade, votarei pela de 15 annos, ainda que pareça dever-se exigir mais: como essa tem sido a opinião geral, eu cedo. (BRASIL, 1982, p. 121)

Ferreira França tomou de novo a palavra e discorreu longamente sobre cada uma das matérias, enfatizando a utilidade do ensino das línguas: a portuguesa, a latina, a grega, a francesa e a inglesa, no que fazia referência à sua experiência como Mestre de seus próprios filhos: "apromptei um de 15 annos com a lingua latina, grega e franceza e demais o sr. Avellino, que ali está, quis principiar a ensinar-lhe allemão"'3. Entre as Línguas Estrangeiras Modernas, Ferreira França tinha preferência pela inglesa, e por razões muito semelhantes às que o Professor Guilherme Tilbury exporia no prefácio de sua Arte Ingleza, publicada no ano seguinte, isto é, como um "anthidoto" contra o veneno do excessivo liberalismo dos franceses ${ }^{4}$ :

Quizera mais que se estudasse francez e inglez, que são depositos de saber, não ha duvida. A lingua ingleza não sei se deve preferir a qualquer outra das 
modernas, por ser a lingua daquella nação onde é plantada a liberdade e a melhor fórma de governo. Deus permitta que nós tenhamos aquella fórma de governo consolidada entre nós! (apoiado geralmente) por ser aquelle, que mais estabilidade pode dar á felicidade do genero humano, sem ameaçar a queda daquelles que occupão o throno. Deus permitta que imitemos esse povo de heróes! (Apoiado, apoiado) (BRASIL, 1982, p. 123)

Sua anglofilia é reiterada nos parágrafos seguintes, nos quais ressalta a qualidade moral dos ingleses e o caráter prático e conciso de sua língua, ao contrário dos "ornatos empolados e superficiaes" do francês:

Os inglezes, meus senhores, distinguem-se pela sua moral, não só entendida, mas praticada. Distinguemse tambem pela sua lingua. A lingua ingleza é grande, é muito grande; por consequencia, devemos aprendel-a. Parece-me mal que, sendo um povo, com que temos tantas relações, quem se destina a maior cultura, deixe de aprender essa lingua. Eu não determinaria que se exigisse logo o exame della, mas que não se conferissem os gráos sem que primeiro se mostrasse ter della conhecimento. Quem ama aquella lingua, ama as cousas que estão nella; porque são tão boas, tão singelamente expostas naquella lingua, com differença tal de expressão, que em nenhuma outra se encontrão. Na singeleza nenhuma lingua se compara com ella: não é só singular pela expressão, mas principalmente pela maneira simples com que emitte as cousas, pela falta de ornato e (deixem-me assim explicar) de cuidado com que apresenta as idéas.

Do pouco que tenho lido dessa lingua, tenho concluido que esse é o seu genio; entretanto vejo outras, como a franceza, que apresentão as cousas, ainda as mais triviaes e baixás com ornatos empolados e superficiaes, de maneira que dão motivo para suspeitar-se sempre da sinceridade do escriptor. (BRASIL, 1982, p. 123) 
Tal simpatia aos ingleses parecia estender-se ao gabinete ministerial do mesmo ano de 1826 - se é que dele não se estendia à Câmara -, podendo assumir a forma de um recurso retórico para justificar a assinatura do Tratado de reconhecimento da Independência do Brasil, como sugere um ofício de 19 de junho remetido às Comissões de Diplomacia e de Fazenda pelo senador e Ministro dos Negócios Estrangeiros Antonio Luís Pereira da Cunha, o Marquês de Inhambupe (1760-1837), dando conta de suas atividades:

A Inglaterra, que tem tomado tanta parte nos negócios do continente americano, mostrou que a

${ }^{5}$ No ano seguinte, com a Decisão n. 17, de 7 de fevereiro, o então Ministro do Império Visconde de S. Leopoldo aprovou os Estatutos e conferiu Licença para o estabelecimento de um Gabinete Inglês de Leitura na Corte do Rio de Janeiro - conforme a lei, tratava-se de promover a formação de "uma casa de leitura, e de uma bibliotheca de livros e periódicos inglezes, a beneficio dos respectivos subscriptores"-, atendendo ao requerimento de dois negociantes ingleses: Stwart Mackay e Carlos Spence (BRASIL, 1878). sua política era sempre favorável para promover a paz neste hemisfério, e as suas relações com o povo brasileiro e europeu foram sempre tão ligadas aos seus próprios interesses, que S. M. Imperial escolheu a Corte de Londres para ser o teatro das primeiras negociações. E, suposto que esta tentativa não seguisse o seu devido efeito, pela oposição que se encontrara no Ministerio português, todavia os esforços de amizade praticados pelo Gabinete britânico e a desteridade com que o Ministerio dirigiu a negociação obtiveram o desejado fim pelo tratado de 29 de agosto do ano passado, celebrado entre os plenipotenciários brasileiros e Sir. Charles Stuart, como plenipotenciario de S. M. Fidelíssima [D. João VI], de que resultou o pleno reconhecimento da nossa Independência. (BRASIL, 1962, p. 17)

Mas o discurso de Ferreira França, na sessão de 11 de agosto, provocou oposições, como a do magistrado Cruz Ferreira:

Em Coimbra não se exige o exame dessas línguas e comtudo, no meu tempo não havia um só estudante, que não soubesse pelo menos traduzir francez; muitos sabião inglez e alguns o allemão e o italiano. A necessidade de ler o que há de bom nessas línguas 
Ao que parece, o discurso de Ferreira França não teve o peso político necessário para ser levado em conta pelos demais deputados, pois, na sessão de 18 de agosto, Januário da Cunha Barbosa apresentou uma redação do projeto na qual o artigo sétimo não contemplava as Línguas Estrangeiras Modernas entre os estudos preliminares. $\mathrm{Na}$ sessão do dia 23 do mesmo mês, entrou em discussão o Plano de Estudos do curso. $\mathrm{O}$ artigo sexto, relativo aos lentes, substitutos e compêndios, foi discutido no dia 26. Nessa mesma sessão, o artigo sétimo passou com a declaração de que os preparatórios exigidos pelos Estatutos do Visconde da Cachoeira seriam alterados somente pela nova Lei, que passava a exigir o exame de geometria, "e não para que se julgasse excluido o da lingua franceza, alli determinado". Vasconcelos propôs um artigo aditivo, no que foi apoiado: "O governo criara as cadeiras dos preparatorios, exigidas por esta lei, que não houverem nos lugares em que são estabelecidos os cursos jurídicos" (BRASIL, 1982, p. 268).

Em 29 de agosto, Clemente Pereira leu nova redação do projeto, que entrou em última discussão no dia 31, apresentando o deputado baiano Araújo Bastos, o Visconde de Fiais, uma emenda relativa à distribuição das doutrinas pelas cadeiras do Curso Jurídico, bem como ao tempo de cada uma delas. Sua proposta foi incorporada à Carta de Lei de 11 de agosto de 1827, assinada pelo Visconde de S. Leopoldo, com a rubrica do Imperador, depois de o projeto ter sido aprovado sem emendas no Senado, a 4 de julho do mesmo ano. Assim ficou a redação final do artigo relativo às matérias exigidas nos exames de preparatórios (art 8.):

Os estudantes, que se quizerem matricular nos Cursos Juridicos, devem apresentar as certidões de idade, por que mostrem ter a de quinze annos completos, e de approvação da lingua franceza, grammatica 
latina, rhetorica, philosophia racional e moral, e geometria. (BRASIL, 1878)

Com a Carta de Lei foi publicado o "Projecto de regulamento ou estatutos para o Curso Juridico creado pelo Decreto de 9 de janeiro de 1825, organizado pelo Conselheiro de Estado Visconde da Cachoeira, e mandado observar provisoriamente nos Cursos Juridicos de S. Paulo e Olinda pelo art. 10 desta lei" 6 . O longo preâmbulo dos Estatutos é bastante esclarecedor a respeito dos objetivos dos recém-criados cursos, que se propunham a ensinar um importante ramo da Instrução Pública: "as doutrinas de jurisprudencia em geral", para que se formassem "sabios Magistrados, e peritos Advogados, de que tanto se

${ }^{6}$ Texto do artigo 10: "Os estatutos do Visconde da Cachoeira ficarāo regulando por ora naquillo em que forem applicaveis, e se não oppozerem á presente lei. A Congregação dos Lentes formará quanto antes uns estatutos completos, que serão submettidos á deliberação da Assembléa Geral" (BRASIL, 1878).

${ }^{7}$ Tal dispositivo foi suplantado pelo artigo oitavo da Carta de Lei, que marcava a idade mínima de 15 anos. carece", além de "dignos Deputados, e Senadores", ou homens aptos para ocupar "os lugares diplomaticos, e mais empregos do Estado". Para tanto, os estudos jurídicos deveriam compreender os princípios elementares do direito natural, público, das gentes, comercial, político e diplomático (BRASIL, 1878).

O Capítulo I dos Estatutos, dedicado aos Estudos Preparatórios, estabelecia, como idade mínima dos estudantes que quisessem matricular-se nas Aulas Jurídicas, 16 anos (art. 1.o $)^{7}$, bem como a obrigatoriedade da apresentação da certidão de exame de todas as matérias exigidas (art. 2.ํ). O estudo das línguas é tratado no artigo seguinte:

O conhecimento perfeito das linguas latina e franceza, sobre dever entrar no plano de uma boa instrucção litteraria, para conhecimento dos livros classicos de toda a litteratura, é peculiarmente necessario para os estudantes juristas. Na primeira está escripto o digesto, o codigo, as novellas, as institutas, e os bons livros de direito romano, o qual, posto que só há de ser elementarmente ensinado neste Curso Juridico, deve de força ser estudado, bem como as instituições de Pascoal José de Mello, e algumas outras obras juridicas de autores de grande 
nota, que andam escriptas na mesma lingua. E na segunda se acham tambem escriptos os melhores livros de direito natural publico, e das gentes, maritimo, e commercial, que covem consultar, mormente entrando estas doutrinas no planno de estudos do Curso Juridico, e sendo escriptos em francez muitos dos livros, que devem por ora servir de compendios. (BRASIL, 1878)

Como se vê, o conhecimento da língua francesa fazia-se necessário por representar um instrumento de acesso aos "melhores livros" de doutrina jurídica, para além da "instruccção litteraria" advinda dos "livros classicos de toda a litteratura", finalidade reservada principalmente ao latim. O caso de Ferreira França parece ser uma exceção, pois sua preferência pelo inglês é justificada pelas supostas qualidades estéticas daquela língua, "muito grande", segundo o deputado, mostrandose entusiasmado com os ingleses.

No entanto, tal preponderância do ensino da língua francesa em relação à Inglesa não impediu que alguns professores de inglês se manifestassem a respeito da matéria, como foi o caso de Guilherme Paulo Tílbury. No mesmo ano em que foi nomeado Mestre de Língua Inglesa da Rainha de Portugal e das Augustas Princesas com o ordenado de 400.000 réis anuais, conforme o Decreto de 4 de abril de 1827 (BRASIL, 1878), Tílbury publicou sua Arte ingleza "offerecida ao illustrissimo senhor visconde de Cayru", não só pelo seu "notório e official zelo" da instrução da mocidade, mas também pelo seu apreço da "Litteratura Britannica", como explica o autor em nota introdutória. A preeminência de tal literatura entre os Estados mais civilizados, complementava, usando a mesma fórmula argumentativa, devia-se não somente às vantagens do comércio, "em que a Nação Ingleza tem indisputavel primazia", mas principalmente à superioridade das obras de "Sciencias Moraes" e de Política, "em que se aprende a distinguir entre a verdadeira liberdade Social, e o desenfreado liberalismo do Seculo" (TILBURY, 1827, p. ii). 
${ }^{8}$ O termo "arte", neste caso, é sinônimo de Compêndio, podendo também ser usado, no Brasil oitocentista, no sentido de expressão estética - no que geralmente é escrito no plural e precedido do adjetivo "belas", como em "Bellas Artes" - e de profissões liberais, como em Colégio das Artes ou Escola de Artes e Ofícios. Nas ocorrências em que é contraposto à "Ciência", como em alguns discursos da segunda metade do século, o termo ganha a acepção de saber ainda nāo sistematizado (OLIVEIRA, 2006).
No prefácio de sua Arte ${ }^{8}$, Tílbury justifica o estudo da Língua Inglesa pela sua utilidade em várias profissões: no comércio, sendo os ingleses "os Freguezes principaes do Brasil"; na política, enquanto o Reino Unido mantivesse a superioridade marítima; na filosofia moral, em que ela poderia oferecer aos filósofos e "Facultativos" "Thesouros preciosissimos"; e mesmo na Teologia, "nas obras de hum Leland, [...], e de um Paley". Mas a sua utilidade maior parece residir no fato de que os autores ingleses serviam de "antidotos" contra a Filosofia francesa (TILBURY, 1827, p. iv). A partir de então, o autor passa a defender a preferência do estudo da Língua Inglesa em relação ao francês, para o que usa de argumentos nem sempre convincentes, como o de que apenas um ou dois dos revolucionários que haviam perturbado a paz do país sabiam inglês:
Eu não digo que se deve deixar de estudar o Francez: porém ao menos deve-se procurar o contraveneno, que he o Inglez. Se, como dizem, a França e a Inglaterra são os dois olhos da Europa, para que contentar-se em ver por hum delles só? Ou quando assim se fizer, escolha-se ao menos aquelle que tem a vista mais comprida. (TILBURY, 1827, p. v)

Com o Aviso de 9 de julho de 1831, Guilherme Tilbury foi nomeado Professor Público da Corte (BRASIL, 1877), o que faz supor que até então havia sido provido interinamente, e pelo Decreto n. 1.111, de 27 de setembro de 1860, o governo mandou satisfazer ao "Padre Tilbury" o ordenado correspondente ao tempo em que esteve privado do exercício da cadeira de Língua Inglesa do Seminário de S. José (BRASIL, 1860). Em 1844, já então "Mestre de Inglez de S. I. D. Pedro Primeiro; de S. M. F. D. Maria Segunda, das SS. PP. Imperiaes e Professor Regio Jubilado", conforme se apresentava na folha de rosto do livro, Tilbury publicou um outro opúsculo: Primeiras regras da lingua ingleza, "tiradas dos melhores authores, e adaptadas ao uso da mocidade brasileira", vendendo os 
exemplares "Na Aula do Author, Rua do Carmo, n. 122"9. Mantendo o princípio segundo o qual mais útil é a "Arte" quanto mais breve ela for, o Padre Tílbury assim justifica sua "artinha" de trinta páginas:

Facil seria amplificar esta artinha, mas então ficaria baldado meu intento, que era, facilitar e abreviar os primeiros passos no estudo desta Lingua. Com esta arte e hum Dicionario, qualquer que entende do seu uso, facilmente chegará a traduzir o Inglez sem precisar de Mestre, e para quem quizer maiores conhecimentos Grammaticaes, não faltão no Rio de Janeiro obras mais extensas. (TILBURY, 1844, p. 30)

Com efeito, antes mesmo de o Padre Tilbury imprimir a sua Arte Ingleza, em 1827, duas outras Gramáticas "mais extensas" haviam sido publicadas por brasileiros durante o período joanino. A primeira, Nova Grammatica Portugueza e Ingleza, "a qual serve para instruir aos portuguezes na lingua ingleza", foi impressa em Londres em 1811 e composta pelo editor do Correio Braziliense Hipólito José da Costa (1774-1822). A segunda, com o mesmo título, e "dedicada á felicidade e augmento da Nação Portugueza", foi escrita por Manoel de Freitas Brazileiro e saiu no ano seguinte, em Liverpool.

Dentre as muitas razões da utilidade de uma gramática inglesa dedicada aos portugueses, Hipólito José da Costa, no prefácio do seu compêndio, destaca sua importância para o negociante, bem como para o "curioso Estudante", na esperança de que ambos pudessem fazer bom uso de um método que lhe parecia ser o mais seguro para se obter e conservar o conhecimento de ambas as línguas: fácil e prático, caracterizando-se pela brevidade. Em apenas um parágrafo, o autor resume todo o conteúdo de sua obra:

Primeiramente se trata das letras, e sua pronunciação; mostrando como se lêm, dando exemplos no estilo Portuguez de soletrar, explicando
9 Tilbury, nessa época, era também professor particular de francês e inglês, como mostra seu anúncio no Almanaque Laemmert para o ano de 1844 (OLIVEIRA, 2006). 
igualmente as vogaes, syllabas, diphtongos, triphtongos, \&c. Depois seguirão-se as declinações, conjugações, regras da syntaxe, etymologia, prosodia, e acentos. Dahi um vocabulario, e diálogos das coisas mais communs, que acontecem na vida. Finalmente ajuntou-se-lhes modellos de cartas sobre o commercio; instrumento de procuração, carta de fretamento, Apólice de seguro, conhecimento de carga; escritura de compromisso; letra de cambio e seu protesto, \&c. (COSTA, 1828, p. i)

Se o Compêndio de Hipólito José da Costa não se difere muito das gramáticas Inglesas dedicadas aos profissionais ou aprendizes do comércio, como a de J. Castro, de 1759 (OLIVEIRA, 2006), tal não é o caso do de Manoel de Freitas Brazileiro, que fez incluir em seu livro, além das matérias propriamente gramaticais - ortografia, etimologia, sintaxe e prosódia -, uma "selecta dos melhores authores". Já no "Prólogo" de sua obra, Freitas faz saber aos desavisados que a Língua Inglesa deveria ser considerada uma das "universaes", "como tem sido a Latina e a Franceza", pois nela se encontram todos os gêneros de leitura, tanto os que embelezam o pensamento quanto os que dilatam as idéias, razão porque se via na obrigação de divulgar entre seus compatriotas o conhecimento de um "Dialecto" tão estranho aos ouvidos dos habitantes do Antártico. Não esquece, porém, de destacar a utilidade comercial da língua, principalmente num momento em que os portos do Brasil estavam franqueados ao comércio com a Inglaterra:

Sendo o conhecimento das Linguas a chave principal e o meio mais efficaz para adquirir relaçoens as mais interessantes, em qualquer condição de vida; e em uma Época tão inesperada, como, vermos os Portos do Brazil franqueados ao Commercio com Inglaterra, fazendo-se deste modo mais ampla e mais extensiva a correspondencia e communicação entre ambas as naçoens; e pelo dezejo que me acompanha, de ser de alguma forma util aos meus nacionaes 
(indaque distante,) pela aquisição de hum Idioma, que principia a ser ouvido e familiarizado entre aquelles, pelas relações do Commercio livre. (BRAZILEIRO, 1812, p. i)

Pela terminologia adotada por Freitas, que enfatiza, no mesmo prólogo, a necessidade do estudo da gramática da língua nacional, percebe-se que o autor tem - ou pelos menos demonstra ter - conhecimentos filológicos mais aprofundados do que Costa ou Tilbury, o que se verifica na "Secção 3.?", dedicada à fonética - "da natureza da articulação, e radical distincção das letras vogaes e consoantes" -, e no breve histórico que faz da gramática, definida pelo autor como "Arte de letras", ou arte de falar e escrever com propriedade e justeza. Vale a pena reproduzir a sua minuciosa definição da voz humana, pela constante referência a termos biológicos:

A Voz humana, hé ar ou respiração lançada das entranhas, e agitada ou modificada por entre a trachéa o o larynx para ser distinctamente ouvida. Traché, hé o tubo que, tocando as fauces externamente, sentimos aspereza e desigualdade. Este hé o que conduz ar às estranhas, para respiração e falla. O topo de trachéa hé o larynx, que consiste de quatro ou sinco cartillagens, as quaes podem dilatarse e ajuntarse, pela acção de certos músculos, que todos operão ao mesmo tempo. No meio do larynx está uma pequena abertura chamada glottis, por onde passa a respiração e a voz. Esta abertura não hé mais que o decimo de uma polegada; e por isso, a respiração vinda das entranhas, deve passar com velocidade. Sendo assim formada a voz; esta hé animada e modificada pela reverberação do paladar, e outras concavidades no interior da bôca e orgaons nasaes: e porque estas partes são mais ou menos bem formadas para a reverberação; a voz será mais ou menos agradavel. (BRAZILEIRO, 1812, p. $26-27)^{10}$
${ }^{10}$ Ao que tudo indica, sua principal fonte, nesse assunto, éo dicionário de Walker. John Walker (17321807) publicou seu Critical Pronouncing Dictionary em 1791, o qual tornou-se a principal referência quanto à pronúncia do inglês, especialmente por incluir uma nota com "Directions to Foreigners" sobre os problemas da pronúncia inglesa para os estrangeiros (HOWATT, 1988, p. 114). 
"Segundo Howatt (1988,

p. 122), Murray

estabeleceu dois novos

princípios na composição de gramáticas inglesas, em sua adaptaçãoda Short introduction to English grammar, with critical notes (1762), de Robert Lowth (1710-1787), destinada ao uso privadoe domésticoe caracterizada por suas notas de rodapé e pela substituiçāo de termos como "ortografia" e "sintaxe" por outros mais simples como "letras", "palavras" e "frases". A primeira foi o sistema de graduação, evidenciado no subtítulo desua gramática: "adapted to the different classes of learners" ("adaptadaàs diferentes classes dealunos"), para o que desenvolveu osistema de notas de Lowth, indicando os diferentes níveis dos estudantes pela variação dos tipos de impressão, e o segundo foi a técnica de exercícios com frases baseadas nos pontos dados em cada lição, como mostram seus English Exercises (1797).

${ }^{12}$ Louis Pierre Siret (17451797), sobrequem, infelizmente, se sabe muito pouco, escreveu mais dois compêndios, Éléments de la Langue Italienne (1797) e uma Grammaire portugaise (1798), sendo um autor muitocitado tanto na literatura pedagógica quanto na legislação e nos compêndios brasileiros do século XIX (OLIVEIRA, 2006).
Reconhecendo que a principal dificuldade dos estrangeiros em aprender a Língua Inglesa consistia na sutileza e rapidez necessárias à pronúncia das palavras, boa parte do compêndio é dedicada à prosódia, para o que o autor se vale de um grande número de regras, tornando seu livro muito mais extenso do que os de Costa e Tílbury, os quais não trazem, como o de Freitas, trechos de autores exemplificando os casos de sintaxe. Ao final do prólogo, fica fácil perceber um de seus modelos, pois cita uma passagem do crítico e professor escocês de retórica e belas letras Hugh Blair (1718-1800) sobre "linguagem e composição", assegurando que aprender a escrever é aprender a pensar (BRAZILEIRO, 1812, p. v). Há também uma espécie de "Apendice" composto de perguntas e respostas sobre gramática e geografia e ainda uma "Advertencia" de duas páginas, mostrando ao estudante ou professor o jeito certo de seguir o método. Os textos escolhidos, quase todos tirados do English Reader de Lindley Murray (1745-1826). ${ }^{11}$ - ou teria sido de Siret ${ }^{12}$ ? -, versam sobre temas como: as vantagens de ler e escrever; glória sólida e verdadeira grandeza; verdadeiros costumes ou polidez; prudência; justiça ou retidão, etc.

Algum tempo depois, saiu o Compendio da Grammatica Ingleza e Portugueza "para uso da mocidade adiantada nas primeiras letras", livro composto por Manoel José de Freitas e impresso no Rio de Janeiro em 1820, com Licença da Mesa do Desembargo do Paço. Tal compêndio é uma versão simplificada do seu livro anterior, a Nova grammatica ingleza e portugueza "dedicada á felicidade e augmento da Nação Portugueza”, impresso em Liverpool em 1812, no qual o autor assina como Manoel de Freitas Brazileiro. No prefácio, Freitas explica seu desejo de ser útil à educação da mocidade num momento em que, "pela Providencia", o Reino do Brasil florescia na agricultura e no comércio com todas as nações, especialmente a inglesa: 
Animado pois por um coração liberal, resolvi preparar este Compendio, considerando o trafico e as relações commerciaes da Nação Portugueza com a Ingleza, e a falta de um Compendio da Grammatica de ambas, para iniciar e facilitar a Mocidade ao uso das duas Linguas, com a clareza, justeza, e simplicidade possivel; e penso que os Pays de familia, desejosos de melhor conhecimento, e em parte, de mais civil e moral Educação nos seus filhos, approvarão este meu desígnio. (FREITAS, 1820, p. i)

Voltando a defender a idéia de que o conhecimento da Língua Inglesa era tão importante quanto o da Língua Latina ou Francesa, o autor argumenta que, se a Língua Latina, até então, tinha servido de condutora aos princípios literários e familiares, e a Francesa era tida como universal, sendo recebida como parte integrante da educação, assim como a música e a dança, a Língua Inglesa deveria ser julgada como necessária à mocidade num país em que se ouvia diariamente o som vocal desse idioma, entrelaçados que estavam os brasileiros em negociações com o Reino Unido. O conhecimento do inglês, além de ser útil ao comércio e ao "trafico civil", serviria também para a leitura de livros de todos os gêneros: "scientificos, moraes, e de Educação polida”. Mas tal conhecimento só poderia ser obtido pela gramática, sem a qual não se podia expressar com "propriedade e justeza" nossos pensamentos:

A Grammatica de qualquer Lingua polida sempre foi a chave, que dá entrada ao conhecimento (por não dizer ao Templo) da Razão humana, e quando estamos bem possuídos de uma, o caminho he mais facil para as outras. Sem alguma Grammatica, seja da Lingua nacional, seja de outra existente, ou morta como a Latina e Grega, não podemos expressar com propriedade e justeza os nossos pensamentos; quero dizer; não con hecemos a propriedade da derivação das palavras; não conhecemos a certeza das letras e syllabas que as compõem; não sabemos collocar em seus proprios lugares os termos ou palavras de huma 
${ }^{13}$ No compêndio, as partes da gramática são explicadas na forma de um diálogo fictício entre um mestre e um discípulo (em inglês com tradução em português). oração ou período; e finalmente, não sabemos muitas vezes pronunciar os mesmos termos com o seu accento devido. (FREITAS, 1820, p. ii)

A língua inglesa, a seu ver, era muito mais fácil de ser aprendida do que a latina, com a qual ele mesmo tinha sentido mais dificuldades, pois um professor "entendido", de boa pronúncia, método e critério, "o que não se adquire em poucos annos", tendo praticado os sons da língua que conhece com os seus nacionais, poderia ser um fiel condutor dos discípulos, suavizando-lhes o caminho. Assim, aprender a ler, falar e escrever aquela língua poderia ajudar a mocidade a dilatar suas idéias "em todo trafico da vida", servindo como uma parte integrante da "boa Educação", definida como um "freio rigoroso", um princípio moral unido à virtude por meio da qual a mocidade poderia adquirir o costume dos bons exemplos, cultivando a sinceridade, a verdade, a humanidade e a justiça (FREITAS, 1820, p. ii-iii). ${ }^{13}$

Essa anglofilia dos intelectuais do parlamento e dos professores/autores de gramáticas inglesas, motivada por pressupostos não apenas estéticos, gramaticais e educacionais, mas também político-econômicos, dado o contexto de negociações nas quais o Brasil estava envolvido com a Inglaterra, de certo contribuíram para que a Língua Inglesa alcançasse o status de disciplina escolar, o que ocorreria em 1831, quando foram aprovados provisoriamente os novos Estatutos para os Cursos de Ciências Jurídicas e Sociais do Império pelo Decreto de 7 de novembro, assinado por Lino Coutinho.

No Capítulo II, encontrava-se a sua novidade: a inclusão do "Inglez, em prosa, e verso" e da "Historia e Geographia" dentre as "Aulas Menores" (art. 1.o), isto é, entre as cadeiras incorporadas aos Cursos Jurídicos, nas quais seriam ensinadas as matérias dos exames de preparatórios: latim em prosa e verso; francês em prosa e verso; inglês em prosa e verso; retórica e poética; lógica, metafísica e ética; aritmética e geometria e história e geografia. Os professores dessas Aulas, nomeados pelo 
poder executivo mediante concurso (art. 2.o), fariam a escolha dos compêndios, ou os arranjariam, "não existindo já feitos", devendo submetê-los ao Diretor, e este à congregação (art. 5.). Quanto ao exercício das cadeiras (art. 7.), teriam lugar "uma vez diariamente", durando as aulas de latim e francês três horas e as demais uma hora e meia (BRASIL, 1877).

As "Aulas Menores" de inglês de ambos os Cursos Jurídicos tiveram um problema para estabelecer-se: a falta de professores, algo que também ocorria com as cadeiras de francês criadas nas províncias. Tal problema ocorreu logo no primeiro ano letivo após a reforma, como se vê pela Decisão n. 41, de 26 de janeiro de 1832, na qual Lino Coutinho esclarece dúvidas ao Diretor do Curso Jurídico de São Paulo, José Arouche de Toledo Rendon, sobre os novos Estatutos. A primeira dúvida dizia respeito à cadeira de inglês e indagava se o professor de francês deveria regê-la, no que resolvia o ministro, em nome da Regência, que por sua vez falava em nome do Imperador D. Pedro II, então com apenas cinco anos de idade:

A mesma Regencia Há por bem, em Nome do Imperador, Declarar a V. Ex., quanto á sua primeira duvida, que o Professor da lingua franceza não é obrigado a ensinar o inglez, visto que, concorrendo para ensinar sómente aquella lingua, debaixo de semelhante proposta obteve a respectiva cadeira, e por isso se reconhece a necessidade de outro Professor que ensine a lingua ingleza. (BRASIL, 1906)

Ficava também estabelecido, com tal Decisão, que os estudantes matriculados naquele ano não eram obrigados aos exames de inglês e história e geografia, "porquanto não ha ainda mestres que ensinem taes doutrinas", algo que estava, segundo o ministro, em conformidade com o artigo primeiro do Capítulo I dos novos Estatutos, que não mencionava as referidas matérias. Com relação à segunda dúvida, sobre a dispensa da geometria para os que quisessem matricular-se naquele ano letivo, a resposta é 
${ }^{1+}$ Trata-se do Liceu do Recife, onde também foram criadas Cadeiras de Línguas Estrangeiras Modernas, segundo um Decreto de 7 de agosto de 1832, que determinava que o Seminário de Olinda fosse transformado em Colégio Preparatório das Artes do Curso Jurídico (BRASIL, 1906). negativa, com a exceção dos alunos já matriculados e reprovados no primeiro ano (BRASIL, 1906).

O problema da falta de professores públicos de inglês também existia em Pernambuco, e persistiu até 1835, como se nota pela Decisão n. 97, de 26 de fevereiro, na qual o ministro Joaquim Vieira da Silva e Souza declarava ao diretor do curso de Olinda, em resposta a um ofício de 8 de janeiro do mesmo ano, que, na falta de professor público de inglês, deveria ser chamada qualquer pessoa habilitada para examinar a matéria. Em tal ofício, o diretor fazia ver os motivos "por que espaçou o concurso da cadeira de Geographia, Chronologia, e Historia”, apontando também os "embaraços" que teve para encontrar os examinadores dos concorrentes às cadeiras de francês e inglês, "visto que nessa Provincia, com quanto existão pessoas muito versadas no conhecimento da lingua ingleza, comtudo só ha um professor della, que é o substituto do Lyceu"14. Com o argumento de que "á lei da necessidade cedem as demais", o ministro mandava que se chamassem pessoas que bem soubessem a Língua Inglesa para verificar o exame a ela referente (BRASIL, 1864a).

As cadeiras de inglês e francês, pelo menos até a década de sessenta, permaneceram regidas pelo mesmo professor, que às vezes também assumia a de latim, como mostra a Decisão n. 489, com a qual saiu o Aviso de 29 de outubro de 1861, assinado por José Ildefonso de Souza Ramos e endereçado ao Diretor da Faculdade de Direito de São Paulo, dispensando ao professor interino da cadeira de latim, francês e inglês do curso de preparatórios das provas de capacidade profissional para ser admitido ao concurso da mesma cadeira. A dispensa baseava-se no título que o candidato tinha de Professor Público da matéria em concurso. Alguns dias depois, com Aviso de 5 de novembro, Souza Ramos declarava àquele diretor que os candidatos que pretendessem inscrever-se para o lugar de substituto dessa cadeira deveriam tirar pontos de todas as três línguas, sendo examinado em todas elas, e não somente em uma, pela sorte (BRASIL, 1862). Foi somente 
em 1864, pelo Decreto n. 3.287, de 14 de junho, que as cadeiras de inglês e francês da Faculdade de São Paulo foram separadas:

Attendendo ao que Me representou a Congregação da Faculdade de Direito da Cidade de S. Paulo sobre a conveniencia de serem ensinadas, em aulas distinctas, as linguas franceza e ingleza; Hei por bem, nos termos do art. 88 do Regulamento de 5 de maio de 1856, que seja dividida em duas a aula preparatoria da mesma Faculdade, que comprehende o ensino das ditas linguas. (BRASIL, 1864b)

\section{Considerações finais}

Todo ensino deve resgatar, em seu aparelho didático, elementos quantitativos ou quantificáveis que possam fornecer escalas de medida em seu sistema de avaliação. Nessa perspectiva, os exames são um componente fundamental no processo de configuração de uma disciplina escolar (CHERVEL, 1990). No Brasil, e no caso específico da Língua Inglesa, tal processo está intimamente relacionado com a institucionalização dos Cursos Jurídicos, cujos Estatutos determinaram a formação do sistema de "Exames de Preparatórios", requisitos indispensáveis para o acesso àqueles cursos. É preciso salientar que a necessidade da reunião das aulas preparatórias num único estabelecimento de ensino forneceu as bases para a implementação dos estudos secundários no país.

Desse modo, o status da Língua Inglesa como disciplina escolar começa a se consolidar somente no momento em que o seu conhécimento passa a ser requisito obrigatório para o ingresso nos Cursos Jurídicos do Império, o que ocorre em 1831. Contudo, os discursos que justificam sua introdução entre as matérias preparatórias a tais cursos passam a circular nos compêndios de inglês e no parlamento brasileiro alguns anos antes. Ao eleger alguns 
modelos estrangeiros para a construção da identidade nacional, num momento em que o país tinha acabado de negociar a sua independência, a anglofilia de alguns intelectuais da época aponta para uma posição política bem precisa, uma vez que se apropria dos autores britânicos, bem como do liberalismo inglês, para defender os interesses da coroa portuguesa e do trono brasileiro, os quais, a todo momento, se viam ameaçados pela má influência da Revolução Francesa.

Sintomática é a defesa das qualidades morais dos ingleses e das potencialidades estéticas da Língua Inglesa pelo deputado Ferreira França, que acusava a Língua Francesa de tratar coisas triviais com ornatos empolados, a ponto de se poder sempre duvidar da sinceridade do escritor. Em seu discurso, a Inglaterra tinha a melhor forma de governo, pois, ao mesmo tempo em que promovia a felicidade do gênero humano, não ameaçava o trono. Posição semelhante tinha o professor de inglês Guilherme Tílbury no prefácio de Arte Ingleza (1827), em que concebia o inglês como contraveneno do francês, língua preferida dos revolucionários que tinham ameaçado a paz do país. Um dado significativo, nesse sentido, é o fato de o compêndio ter sido dedicado ao Visconde de Cairu (1756-1835) pelo seu apreço da "Litteratura Britannica".

Muitos autores de compêndios de inglês do período buscavam motivar seus discípulos ou leitores justificando seu ensino pelo caráter utilitário da língua e pela obrigatoriedade do seu conhecimento em determinados estudos superiores - e até afirmando que ela deveria ser considerada uma das "universaes", "como tem sido a Latina e a Franceza", conforme as palavras de Manoel de Freitas Brazileiro no prefácio de sua Nova Grammatica Portugueza e Ingleza, de 1812. No entanto, a preponderância da Lingua Francesa, que se mostrava pela sua maior procura nos exames de preparatórios e na maior disponibilidade de professores, públicos como particulares, oferecia obstáculos à institucionalização do ensino de inglês no país, que só pôde ser iniciada em 1831. 
Para tal institucionalização, como se pôde ver, muito concorreram os discursos dos parlamentares do Império, bem como dos professores/autores de gramáticas inglesas, que justificavam sua valorização e inclusão nos exames de preparatórios movidos não somente por fatores bastante concretos à época, tais como as relações políticas e comerciais entre o Império independente e a Inglaterra, mas também por uma representação de que a Língua Inglesa, sendo o idioma de um país que se tinha por modelo de uma monarquia liberal, poderia desempenhar um papel importante na formação da "mocidade brasileira".

Mesmo assim, as facilidades do mercado, o qual era muito mais rentável para aqueles que ensinavam os rudimentos gramaticais das várias línguas exigidas nos exames de preparatórios - latim, francês, inglês e português, a partir da década de setenta -, a despeito dos que se dedicavam com afinco a somente uma língua, condicionaram a formação da figura do professor polivalente de línguas, o que fez com que a cadeira de inglês das aulas preparatórias sempre carecesse de pessoal qualificado. Essa foi a principal razão pela qual, pelo menos até a década de 1860, o francês e o inglês - e às vezes também o latim - fossem ensinados pelo mesmo professor nas aulas preparatórias anexas aos Cursos Jurídicos do Império brasileiro. 


\section{Referências}

BRASIL. 1860. Coleção das Leis do Imperio do Brasil de 1860.

Rio de Janeiro: Typographia Nacional.

.1862. Coleção das Leis do Imperio do Brasil de 1861.

Rio de Janeiro: Typographia Nacional.

. 1864a. Coleção das Leis do Imperio do Brasil de

1835. Rio de Janeiro: Typographia Nacional.

1864b. Coleção das Leis do Imperio do Brasil de

1864. Rio de Janeiro: Typographia Nacional.

1874. Assembléa Constituinte de 1823. Rio de Janeiro:

Typographia do Imperial Instituto Artistico, tomo quinto.

. 1877. Coleção das Leis do Imperio do Brasil de 1831.

Rio de Janeiro: Typographia Nacional.

1878. Coleção das Leis do Imperio do Brasil de 1827.

Rio de Janeiro: Typographia Nacional.

. 1906. Coleção das Leis do Imperio do Brasil de 1832.

Rio de Janeiro: Imprensa Nacional.

1962. Organizações e programas ministeriais: regime

parlamentar no Império. 2. ed. Rio de Janeiro: Ministério da Justiça e Negócios Interiores / Arquivo Nacional.

. 1885. Coleção das Leis do Imperio do Brasil de 1825.

Rio de Janeiro: Imprensa Nacional.

. 1982. Annaes do Parlamento Brazileiro. Câmara dos

Srs. Deputados. Primeiro anno da primeira legislatura. Sessão de 1826. Tomo Quarto. Brasília: Câmara dos Deputados.

BRAZILEIRO, Manoel de Freitas. Nova grammatica inglezae portugueza dedicada á felicidade e augmento da Nação

Portugueza. Selecta dos melhores authores, por Manoel de Freitas Brazileiro. Liverpool: G. F. Harris's Viuva e Irmãos, 1812.

CHERVEL, André. História das disciplinas escolares: reflexões sobre um campo de pesquisa. Tradução Guacira Lopes Louro. Teoria \& educação. Porto Alegre, n. 2, 1990, p. 177-229.

COSTA, Hipólito José da. Nova grammatica portugueza e ingleza a qual serve para instruir aos portuguezes na lingua ingleza. Nova edição revista e consideravelmente augmentada. Londres: J. Collingwood, 1928. 
FREITAS, Manoel José de. Compendio da grammatica ingleza e portugueza para uso da mocidade adiantada nas primeiras letras. Rio de Janeiro: Impressão Regia, 1820.

HOWATT, A. P. R. A history of English language teaching. 3. ed. Oxford: Oxford University Press, 1988.

OLIVEIRA, Luiz Eduardo Meneses de. A instituição do ensino das línguas vivas no Brasil: o caso da língua inglesa (18091890). Tese de Doutorado, Programa de Estudos PósGraduados em Educação: História, Política, Sociedade, Pontifícia Universidade Católica de São Paulo, 2006. Disponível em: http://www.sapientia.pucsp.br/tde busca/ arquivo.php?cod Arquivo=2255.

TILBURY, Guiherme Paulo. Arte ingleza offerecida ao illustrissimo Senhor Visconde de Cayru. Rio de Janeiro: $\mathrm{Na}$ Typographia Imperial e Nacional, 1827.

tiradas dos melhores authores, e adaptadas ao uso da mocidade brasileira. Rio de Janeiro: Typ. do Diario de N. L. Vinna, 1844.

VAMPRÉ, Spencer. Memorias para a historia da academia de São Paulo. São Paulo: Livraria Academica / Saraiva \& Cia, 1924. 